\title{
Posicionamento por DGPS: experimentos para avaliação das técnicas RDS, NTRIP e DGPS
}

\section{em rede}

\author{
DGPS Positioning: experiments to evaluate the RDS, NTRIP and DGPS network techniques
}

\author{
Mauricio Ihlenfeldt Sejas ${ }^{1}$ \\ Eno Darci Saatkamp ${ }^{2}$ \\ Jaime Freiberger Júnior ${ }^{2}$
}

\author{
${ }^{1}$ Instituto Federal Catarinense (IFC), Rio do Sul, SC, Brasil. \\ ${ }^{2}$ Universidade Federal de Santa Maria (UFSM), Santa Maria, RS, Brasil. \\ msejas@ifc-riodosul.edu.br, enosaat@ hotmail.com, jaimebrasil@ hotmail.com
}

\begin{abstract}
RESUMO - Neste trabalho são mostrados os resultados de experimentos baseados em diferentes técnicas de transmissão de correções diferenciais a partir de uma estação GPS de referência, bem como resultados de um posicionamento que utiliza o conceito de DGPS em rede, no modo pós-processado. Na utilização das técnicas NTRIP e RDS, constatou-se que a acurácia média obtida pela técnica DGPS-NTRIP foi cerca de $15 \%$ melhor ante a técnica DGPS-RDS. Utilizando o conceito de DGPS em rede, os resultados dos posicionamentos mostraram que o emprego de correções em rede promoveu melhora entre 1,9 e 5,3 vezes na acurácia, e entre 1,5 e 1,75 vezes na precisão, em comparação ao posicionamento por linha de base simples.
\end{abstract}

\section{Palavras-chave: GPS, DGPS, RDS, NTRIP}

ABSTRACT - Results from differential positioning experiments obtained using real-time DGPS method performed in field measurements are the subject of this paper. The ways to transmit differential corrections as well as some results using the DGPS network concept in the post-processed mode are presented and discussed. It was noticed that the positioning accuracy was ca. 15\% better using the DGPS-NTRIP technique in comparison to DGPS-RDS. By using DGPS network technique, the positioning accuracy was enhanced from 1,9 up to 5,3 times. Also a precision improvement from 1,5 up to 1,75 times was verified if compared to the single baseline positioning.

Keywords: GPS, DGPS, RDS, NTRIP

\section{INTRODUÇÃO}

Os serviços de posicionamento em tempo real pelo GNSS foram beneficiados com o desenvolvimento de soluções baseadas nas chamadas correções diferenciais, que fundamentam, por exemplo, os métodos RTK e DGPS na obtenção de coordenadas geodésicas precisas.

Implementadas via enlace de comunicação que operam nas faixas de frequências de rádio, as correções diferenciais nestes métodos podem sofrer degradação ou interrupções parciais em função do alcance e da qualidade da transmissão. Estes fatores, somados a outros erros correlacionados (e.g., erros orbitais e erros atmosféricos), limitam a eficácia das correções, e, com isso, a confiabilidade do processamento em tempo real.

Nos últimos anos surgiram alternativas ao emprego das frequências de rádio exclusivas para transmissão das correções diferenciais, como por exemplo, o padrão denominado RDS (Radio Data System) utilizado pela primeira vez em 1987 na Suécia (OGATA et al., 1992) e especificado desde 1990 para a transmissão de dados digitais de qualquer natureza. O RDS foi concebido inicialmente para prover serviços adicionais a usuários pela utilização de uma nova geração de receptores de rádio capazes de realizar operações em seu funcionamento de modo automático pela utilização das informações providas pelo sistema. Na Europa, o RDS foi largamente utilizado também na transmissão de correções diferenciais para o posicionamento DGPS, agregando a vantagem do baixo custo de implantação ante sua limitada capacidade de transmissão de dados (SAATKAMP, 2003). Especificamente na Alemanha, há um processo de substituição do uso do RDS pelo NTRIP.

Visando substituir o enlace de rádio e melhorar a precisão das medições GNSS, a Agência Federal de Cartografia e Geodésia da Alemanha apresentou, em junho de 2003, um novo conceito para a provisão de correções diferenciais em tempo real: o NTRIP (Network Transport of RTCM via Internet Protocol), um protocolo genérico que possibilita a transmissão de dados de correção DGPS ou RTK via internet, a qual pode ser acessada em campo por telefone celular pelo sistema GPRS ou outras tecnologias (GEBHARD e WEBER, 2003). 
No âmbito brasileiro, alguns trabalhos científicos comprovaram a viabilidade destas técnicas e os benefícios do estabelecimento de uma rede de referência nacional precisa e abrangente. $\mathrm{O}$ presente estudo apresenta os resultados de dois experimentos independentes: o primeiro trata do posicionamento DGPS em tempo real utilizando tanto o protocolo NTRIP como o sistema RDS para a comunicação dos dados de uma estação de referência para as estações móveis; e o segundo experimento, por sua vez, emprega o conceito de DGPS em rede com processamento dos dados no modo pósprocessado.

\section{GPS DIFERENCIAL (DGPS)}

O DGPS é um método de posicionamento em tempo real que faz uso de pelo menos dois receptores GPS. Um deles é instalado sobre um ponto de coordenadas conhecidas, quando passa a ser designado como "estação base" ou "estação de referência", e o outro percorre o caminho ou os pontos que se deseja obter as coordenadas (estação móvel ou estação usuária).

A estação base tem a função de determinar correções de pseudodistância (PRC - Pseudorange Corrections) e as variações das correções das pseudodistâncias (RRC Range Rate Corrections), que são transmitidas à estação usuária em tempo real. Esta, por sua vez, faz uso das PRC e RRC para determinar suas coordenadas (HOFMANNWELLENHOF, 2001).

O modelo básico para as observações de pseudodistância do código, entre uma estação qualquer $R$, e um satélite $s$, pode ser escrito na forma simplificada (WÜBBENA et al., 2001):

$$
P D_{R}^{s}=\rho_{R}^{s}+\delta R_{R}^{s}+\delta D_{R}^{s}+\delta E_{R}^{s}+\varepsilon_{R}^{s}
$$

onde:

$P D_{R}^{s}$ pseudodistância do código entre a estação $R$ e o satélite $s$;

$\rho_{R}^{s} \quad$ distância geométrica entre a estação $R$ e o satélite $s$;

$\delta R_{R}^{s} \quad$ erros de relógio;

$\delta D_{R}^{S} \quad$ erros dependentes de distância;

$\delta E_{R}^{s} \quad$ erros dependentes de estação;

$\varepsilon_{R}^{s} \quad$ ruídos e parâmetros não modelados.

O termo referente aos erros de relógio na Eq. (1) aparece devido ao não sincronismo do relógio do satélite com o relógio do receptor. Os erros dependentes de distância compreendem os erros de órbita e refração troposférica e ionosférica, que são fortemente correlacionados para linhas de base curtas. Assim, a influência destes erros cresce em função do aumento da linha de base que separa a estação de referência da estação móvel. Os erros dependentes de estação estão realacionados ao efeito do multicaminho e da variação do centro de fase da antena. O último termo da equação trata dos ruídos e parâmetros não modelados. Seeber (2003) apresenta a correção de pseudodistância para uma época $t$ conforme a Eq. (2):

$$
P R C_{R}^{S}(t)=P D_{R}^{s}(t)-\rho_{R}^{s}(t)
$$

onde a distância geométrica entre a antena GPS na estação $R$ e o satélite $s$ é calculada com as coordenadas precisas da estação $R$ e as coordenadas dos satélites obtidas por meio das efemérides transmitidas.

Sendo $t_{0}$ a época de geração da mensagem, a PRC para uma época $t$ qualquer é calculada pela Eq. (3), que considera a variação da PRC para um intervalo de tempo $t$ - $t_{0}$, definido como latência. Quanto maior a latência, menor a acurácia esperada para o levantamento.

$$
P R C_{R}^{s}(t)=P R C_{R}^{s}\left(t_{0}\right)+R R C_{R}^{s}\left(t_{0}\right)\left(t-t_{0}\right)
$$

A PRC calculada é utilizada na correção da pseudodistância observada pela estação usuária segundo a equação:

$$
P D C_{R}^{s}(t)=P D_{R}^{s}(t)-P R C_{R}^{s}(t)
$$

onde o termo PDC representa a pseudodistância corrigida dos maiores efeitos referentes ao erros dependentes de distância.

\subsection{DGPS em rede}

Tradicionalmente, o posicionamento GPS é realizado no modo denominado "linha de base simples", isto é, uma ou várias estações usuárias são posicionadas em relação a uma única estação de referência. Porém, existe a possibilidade de se empregar uma rede de estações de referência para modelar localmente alguns dos erros presentes no posicionamento, a qual será tratada neste trabalho como "DGPS em Rede".

As correções de pseudodistância geradas individualmente por cada uma das estações da rede são utilizadas para estimar os coeficientes do modelo matemático que representa os erros localmente. Com estes coeficientes e as coordenadas aproximadas da estação usuária, correções de pseudodistância são calculadas (interpoladas) e utilizadas para corrigir as pseudodistâncias originais da estação usuária.

Diversos modelos matemáticos podem ser empregados para interpolar os erros estimados em rede. Um polinômio de três termos do tipo $y=a x+b y+c$ é um modelo matemático que pode ser empregado na modelagem dos erros quando existem três ou mais estações de referência.

Como as coordenadas geodésicas (latitude e longitude) da estação de referência $R$ são conhecidas, pode-se escrever a equação de observação como:

$$
P R C_{R}^{s}(t)=a^{s}(t) \cdot \varphi_{R}+b^{s}(t) \cdot \lambda_{R}+c^{s}(t)
$$


onde $a, b$ e $c$ são os coeficientes do modelo matemático tratados neste trabalho como "coeficientes de rede". Para $n$ estações de referência $(n>3)$ um sistema de equações pode ser formado:

$$
\left|\begin{array}{c}
P R C_{R 1}^{s}(t) \\
P R C_{R 2}^{s}(t) \\
\vdots \\
P R C_{R n}^{s}(t)
\end{array}\right|=\left|\begin{array}{ccc}
\varphi_{R 1} & \lambda_{R 1} & 1 \\
\varphi_{R 2} & \lambda_{R 2} & 1 \\
\vdots & \vdots & \vdots \\
\varphi_{R n} & \lambda_{R n} & 1
\end{array}\right| \cdot\left|\begin{array}{c}
a^{s}(t) \\
b^{s}(t) \\
c^{s}(t)
\end{array}\right|
$$

Para cada satélite, os coeficientes de rede podem ser estimados em cada época pelo método dos mínimos quadrados. Uma vez determinados os coeficientes de rede, as correções de pseudodistância para a posição aproximada da estação usuária $(U)$ são interpoladas segundo a Eq. (7) e posteriormente utilizadas na correção das observações originais da estação.

$$
\operatorname{PRC}_{U}^{s}(t)=a^{s}(t) \cdot \varphi_{U}+b^{s}(t) \cdot \lambda_{U}+c^{s}(t)
$$

Outros estudos e experimentos sobre DGPS em rede realizados no Brasil podem também ser encontrados em Dalbelo (2010).

\section{SISTEMAS PARA TRANSMISÃO DAS CORREÇÕES DGPS}

Para que seja possível realizar o DGPS, é necessário um sistema de comunicação que transmita os dados de correção diferencial desde a(s) estação(ões) de referência até $\mathrm{a}(\mathrm{s})$ estação(ões) usuárias. Teoricamente qualquer sistema de comunicação pode ser usado, uma vez que os dados de correção a ser transmitidos geralmente são encapsulados em protocolos ou padrões específicos para tal aplicação. Especificamente no GNSS, são utilizadas as diversas versões de padrões recomendados pelo Subcomitê $\mathrm{n}^{\circ} 104$ da Radio Technical Commision for Maritime Services - RTCM SC-104. Praticamente todos os receptores GNSS estão aptos a operar com pelo menos uma versão desse protocolo. Na prática, há diversos sistemas de comunicação usados na transmissão de dados de correção encapsulados em alguma versão RTCM. Como exemplos desses sistemas de transmissão, citam-se o rádio-modem dedicado, os rádio-faróis da marinha, os serviços via satélite, a subportadora de emissoras em radiodifusão FM - denominado Radio Data System (RDS) - e, ultimamente, um sistema bastante difundido denominado Networked Transport of RTCM via Internet Protocol (NTRIP). Algumas características destes dois sistemas de comunicação - RDS e NTRIP - são apresentadas a seguir.

\subsection{Transporte das mensagens RTCM via RDS}

O Sistema de Radiotransmissão de Dados - Radio Data System (RDS) - é um padrão que foi desenvolvido a partir de 1990 para a transmissão de dados na forma digital pela modulação da subportadora do sinal de radiodifusão de emissoras de radiodifusão sonora em frequência modulada - FM. O documento CENELEC, EN 50067: 1998 - Specifications of the Radio Data System (RDS) for VHF/FM broadcasting, European Committee for Electrical Standardisation apresenta as especificações usadas internacionalmente. Este documento foi traduzido pela Agência Nacional de Telecomunicações - ANATEL - que elaborou uma compilação destas especificações adaptadas aos padrões brasileiros, denominada Especificação Técnica para a Radiotransmissão de Dados Mediante Utilização do Canal Secundário de Emissora de Radiodifusão Sonora em Freqüência Modulada - RDS (Saatkamp, 2003). A Resolução ANATEL no 349 de 25/set/2003, aprovou o regulamento técnico para este tipo de radiodifusão. O RDS possibilita diversas aplicações, algumas previstas e padronizadas, de forma geral usadas no controle automatizado e identificação de programas e de emissoras de rádio em rede assim como informações sobre sua programação apresentadas no mostrador do receptor de rádio do usuário. E há espaço alocado para outras aplicações abertas, denominadas Open Data Aplications - ODA. É em um grupo ODA que os dados de correção para DGPS são inseridos e transmitidos. O RDS conta com um potencial de aplicação que não foi totalmente explorado no Brasil, principalmente na transmissão de correções diferenciais para o posicionamento pelo método DGPS além das outras aplicações previstas. Uma característica do sistema é, por um lado, o investimento não muito alto para sua implantação uma vez que em parte ele utiliza a estrutura de emissoras de radiodifusão FM já existente. Entretanto, também são necessários equipamentos codificadores e decodificadores, e moduladores e demoduladores específicos. Além disso, o sistema é bastante limitado quanto à capacidade de transmissão dos dados $(673,7$ bits de informação para ser divididos nos diferentes grupos de aplicação). Apenas para exemplificar, um grupo ODA permite a transmissão de "pacotes" (geralmente um a cada segundo) de somente 37 bits.

Para a aplicação específica no posicionamento DGPS há (ou houve) três formatos ou sistemas proprietários. Um sistema desenvolvido na América do Norte pela Differential Corrections, Inc - DCI, cujos serviços aparentemente foram desativados há poucos anos. Outro sistema, desenvolvido na Alemanha por uma comissão formada por técnicos e engenheiros do LVermA NRW (Landesvermessungsamt Nordrhein-Westfalen) e da WDR (Westdeutscher Rundfunk) denominado RASANT (Radio Aided Satellite Navigation Technique), que por vários anos oferecia cobertura do serviço em todo o país (mas também está sendo descontinuado). Um terceiro formato foi desenvolvido no Brasil por Saatkamp (2003), denominado DGPS Brasileiro por RDS - DGPSBRDS. A Fig. 1 ilustra a estrutura básica do posicionamento DGPS pela utilização do RDS na transmissão das correções diferenciais. $\mathrm{Na}$ sequência são apresentados alguns resultados de testes do DGPSBRDS que em razão de diversos fatores não foi sistematicamente implantando como um serviço no Brasil. Um dos fatores é a inexistência de políticas públicas que orientem ações para 
investimento maciço em Cartografia bem como a falta de integração dos grupos de pesquisa nos âmbitos público e privado para o desenvolvimento de sistemas e serviços desta natureza de forma eficaz e abrangente. Outro fator é o surgimento de um novo sistema de comunicação de dados, em princípio mais efetivo que o RDS, denominado NTRIP, que está sendo adotado na maior parte do mundo (item 3.2). Em alguns países da Europa e na América do Norte o RDS ainda é amplamente utilizado para desempenhar suas aplicações originais. Uma importante aplicação do RDS naqueles países é o canal de mensagem de tráfego (Traffic Message Channel - TMC), que transmite informações atualizadas sobre fluxo de trânsito. Elas permitem otimizar rotas automática e dinamicamente em sistemas de navegação veiculares.



Figura 1 - Estrutura básica para o posicionamento DGPS utilizando FM-RDS (Fonte: SAATKAMP, 2003).

\subsection{Transporte das mensagens RTCM por rede via protocolo internet - NTRIP}

O Networked Transport of RTCM via Internet Protocol - o NTRIP, é um protocolo desenvolvido pela Agência Federal de Cartografia e Geodésia (BKG Bundesamt für Kartographie und Geodäsie) da Alemanha para a transmissão de mensagens RTCM via internet em tempo quase real, permitindo conexões simultâneas entre equipamentos usuários (clientes) com um servidor conhecido como NTRIP CASTER (Fig. 2). É possível receber via internet as mensagens RTCM de estação(ões) de referência diretamente em um microcomputador. Para se aplicar os dados de correção diferencial a um receptor GNSS, são utilizados programas específicos, como por exemplo, o programa disponibilizado na página eletrônica da BKG/NTRIP (GDC, 2012). Entretanto, atualmente existem no mercado muitos receptores GNSS com sistema de comunicação interno que possibilita receber os pacotes RTCM por meio do NTRIP e pela tecnologia GSM (Sistema Global para Comunicações Móveis GSM). Esses equipamentos possuem um conector que aceita um cartão SIM (Subscriber Identity Module) da rede de telefonia celular, por meio da qual é realizado o acesso à internet e ao servidor NTRIP, sem a necessidade de um computador. Em relação aos outros sistemas de comunicação de dados, o NTRIP é atualmente um meio de transmissão bastante eficaz, dentre outros aspectos, por ser prático, relativamente econômico, permitir taxas adequadas de transmissão de dados e possibilitar que muitos usuários tenham acesso simultâneo a uma mesma estação de referência. Entretanto, uma vez que o acesso ao NTRIP é condicionado pela conexão à internet, na prática esta dependência se torna uma restrição aos levantamentos em regiões sem sinal da rede de telefonia.

Na Fig. 2 é apresentada a estrutura básica do NTRIP, constituído dos seguintes componentes:

a) NTRIP SOURCE: é um sistema que disponibiliza um fluxo de dados GNSS continuamente. Uma fonte de dados desse tipo consiste geralmente de um receptor GNSS gerando e enviando dados RTCM de uma estação de referência;

b) NTRIP SERVER: é utilizado para transferir dados GNSS de um NTRIP SOURCE (estação de referência) para um NTRIP CASTER;

c) NTRIP CASTER: é basicamente um servidor HTTP, que organiza o sistema NTRIP SOURCE e controla os acessos com o NTRIP CLIENT. Esse acesso é realizado sob permissão por identificação e senha do usuário previamente cadastrado;

d) NTRIP CLIENT: é o aplicativo do usuário do servidor. Com ele é possível acessar os dados de um NTRIP CASTER, escolher a estação de referência desejada e configurar opções locais daquilo que o usuário deseja realizar com os dados recebidos.



Figura 2 - Diagrama da estrutura de funcionamento do NTRIP (Fonte: GDC, 2012).

No Brasil, o IBGE disponibiliza um serviço público de acesso ao NTRIP. As estações de referência ativas pertencentes à Rede Brasileira de Monitoramento Contínuo - RBMC - situadas nas principais capitais e em algumas cidades do interior fornecem o fluxo NTRIP (IBGE, 2012). Além do IBGE, há também instituições privadas que dispõem do serviço de transmissão de correções diferenciais via NTRIP no Brasil.

\section{EXPERIMENTOS}

Neste trabalho são apresentados os resultados de dois experimentos realizados de forma independente. $\mathrm{O}$ primeiro deles trata do posicionamento DGPS em tempo real, onde foram utilizados os sistemas NTRIP e RDS, independentemente, para transmissão das correções 
diferenciais de uma estação de referência para as estações usuárias. O segundo experimento baseou-se no conceito de DGPS em rede onde o processamento dos dados ocorreu no modo pós-processado.

\subsection{DGPS em tempo real}

Estes experimentos foram realizados na Universidade Federal de Santa Maria (UFSM), utilizando os sistemas RDS e NTRIP para a transmissão das correções diferenciais. $\mathrm{O}$ objetivo foi determinar a precisão (pelo desvio-padrão) e a acurácia (pela média dos desvios absolutos) de posicionamentos GPS com a transmissão de correções diferenciais empregando cada um dos dois sistemas. E ao final, avaliar e comparar os resultados em termos de eficácia na qualidade do posicionamento. A Fig. 3 ilustra o diagrama esquemático utilizado (GUTERRES e SAATKAMP, 2009).

Realizaram-se simultaneamente levantamentos DGPS com dois receptores idênticos que rastreiam o código C/A (receptores A e B, marca Garmin, modelo Etrex), instalados lado a lado no Marco do Setor de Geodésia - MSG - da UFSM, empregando a mesma fonte de correções diferenciais: a estação SMAR, pertencente à RBMC. Cada receptor recebeu as correções diferenciais por um dos dois meios de comunicação: a internet (uso do NTRIP); e o transmissor de rádio FM (uso do RDS). No caso do NTRIP, utilizou-se o programa NTRIP CLIENT (sistema operacional Windows) para o acesso aos dados, cujo CASTER situava-se no Instituto Brasileiro de Geografia e Estatística - IBGE - no Rio de Janeiro-RJ.



Figura 3 - Diagrama esquemático da estrutura utilizada para investigações DGPS usando NTRIP e RDS.

Com o objetivo de avaliar a mudança na precisão do posicionamento, intercalaram-se períodos com rastreios nos modos diferencial e absoluto. O comportamento da precisão estimada pelo receptor é apresentado nas Figs. 4 e 5. Na aplicação de ambas as técnicas (NTRIP e RDS), observa-se claramente uma melhora nas estimativas de precisão no modo de posicionamento diferencial (Dif.) em relação ao modo de posicionamento absoluto (Abs.).

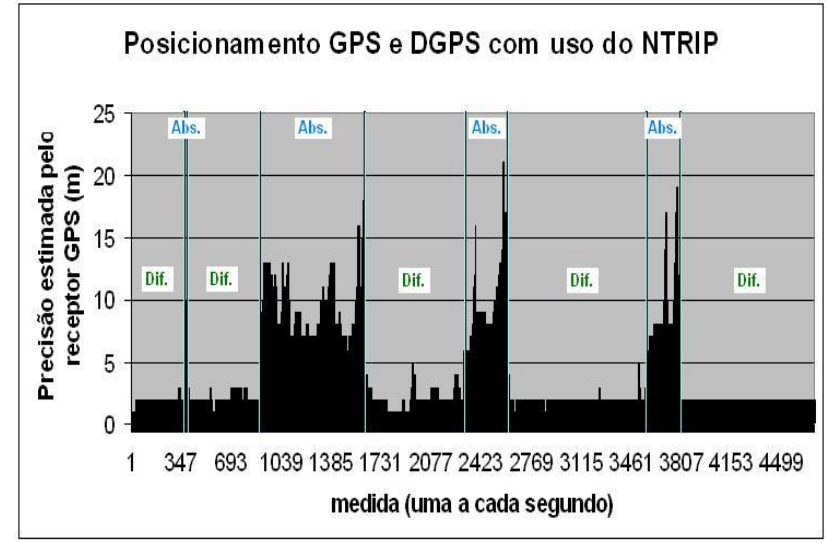

Figura 4 - Estimativa de precisão posicional GPS e DGPS com uso do NTRIP.

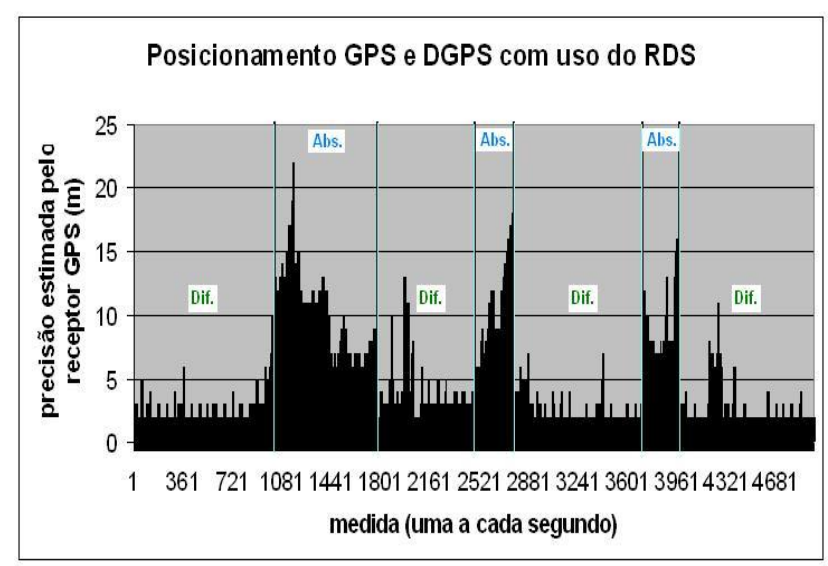

Figura 5 - Estimativa de precisão posicional GPS e DGPS com uso do RDS.

Entretanto, ao invés da precisão estimada, a análise da acurácia é mais realista. Para isso, foram calculados os desvios entre os valores das coordenadas medidas e os valores das coordenadas verdadeiras, cálculo este efetuado para cada medida DGPS dos receptores. As Figs. 6 e 7 mostram o comportamento estatístico da acurácia, onde a distribuição acumulada dos erros no posicionamento se apresentam em faixas de $1 / 3 \mathrm{em} 1 / 3$ do metro, respectivamente, pelo uso do NTRIP e pelo uso do RDS.

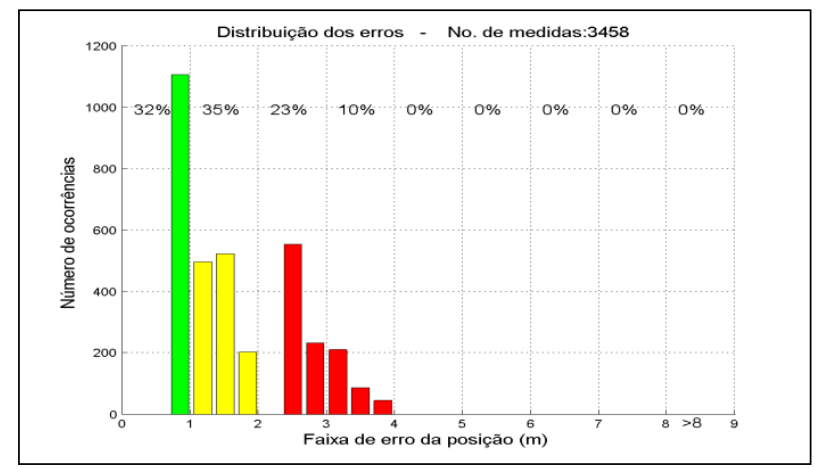

Figura 6 - Distribuição dos erros (acurácia) para o rastreio pela técnica DGPS-NTRIP. 


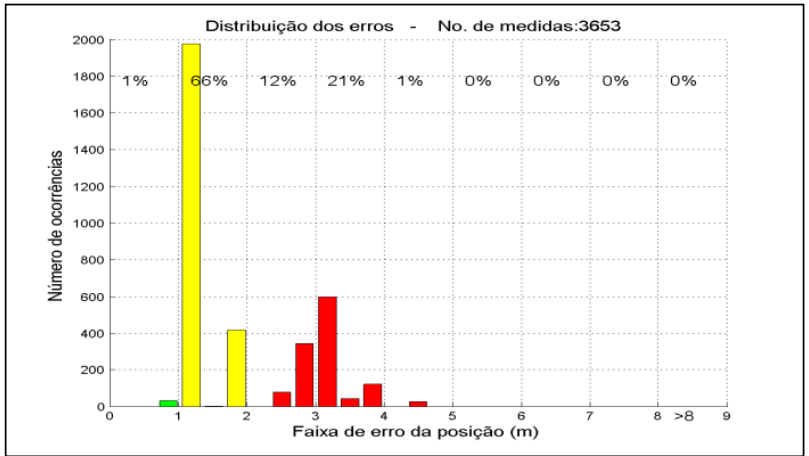

Figura 7 - Distribuição dos erros (acurácia) para o rastreio pela técnica DGPS-RDS.

Na técnica DGPS-NTRIP observa-se que 67\% das medidas ficaram com erro de posição inferior a $2 \mathrm{~m}$, e $100 \%$ abaixo de $4 \mathrm{~m}$. Na técnica DGPS-RDS, tais valores de distribuição foram semelhantes (Fig. 7), onde cerca de $1 \%$ das medidas apresentou erro superior a $4 \mathrm{~m}$.

No quadro 1 são apresentados os valores quantitativos de precisão (desvio-padrão) e acurácia (média dos desvios absolutos) obtidos por cada uma das técnicas DGPS.

Quadro 1 - Resultados dos posicionamentos pelas técnicas DGPS- NTRIP e DGPS-RDS

\begin{tabular}{|l|c|c|c|c|c|c|}
\cline { 2 - 7 } \multicolumn{1}{c|}{} & \multicolumn{2}{|c|}{ DGPS com NTRIP } & \multicolumn{3}{c|}{ DGPS com RDS } \\
\cline { 2 - 7 } \multicolumn{1}{c|}{} & lat & long & $\begin{array}{c}\text { Posição } \\
\text { 2D }\end{array}$ & lat & long & $\begin{array}{c}\text { Posição } \\
\text { 2D }\end{array}$ \\
\hline $\begin{array}{l}\text { Desvio- } \\
\text { Padrão } \\
\text { (m) }\end{array}$ & 1,02 & 1,57 & 1,88 & 1,23 & 0,85 & 1,49 \\
\hline $\begin{array}{l}\text { Média } \\
\text { dos } \\
\text { desvios } \\
\text { absolut } \\
\text { os (m) }\end{array}$ & 0,87 & 1,37 & 1,62 & 1,05 & 1,57 & 1,89 \\
\hline
\end{tabular}

Observa-se que o desvio-padrão (ou precisão) obtido com o NTRIP foi sensivelmente maior àquele obtido com o $\operatorname{RDS}(1,88$ e 1,49 m respectivamente). Entretanto, a acurácia média obtida pela técnica DGPS-NTRIP foi cerca de $15 \%$ melhor que a acurácia obtida pela técnica DGPS-RDS, com valores, respectivamente, de 1,62 e 1,89 m. Contudo, em ambos os casos a acurácia média foi melhor que $2 \mathrm{~m}$.

\subsection{DGPS em rede (pós-processado)}

No experimento relacionado com o DGPS em rede, foram selecionadas seis estações GNSS da RBMC, localizadas nos estados da Região Sul do Brasil (Fig. 8): PRGU (PR), SCCH (SC), SCLA (SC), IMBT (SC), SMAR (RS) e POAL (RS). Destas, SCLA e SCCH foram utilizadas como estações usuárias, enquanto as demais como estações de referência. Nesta configuração, a maior distância entre as estações da rede é 530 km (PRGUSMAR). A estação de referência mais próxima da estação SCLA é a estação IBMT $(170 \mathrm{~km})$ e a estação mais próxima da estação SCCH é a estação PRGU $(224 \mathrm{~km})$. Observa-se que a estação SCCH está localizada geograficamente fora da rede, portanto as correções de pseudodistância deverão ser extrapoladas para esta estação.

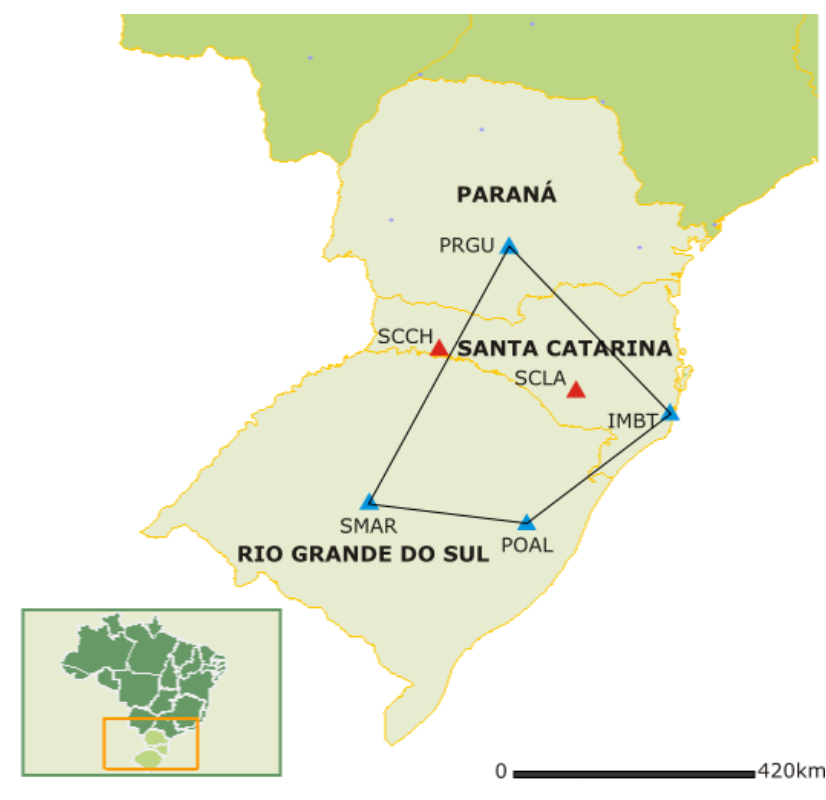

Figura 8 - Configuração da rede formada pelas quatro estações de referência PRGU, IMBT, SMAR e POAL e pelas duas estações móveis SCCH e SCLA.

Os resultados apresentados nesta seção referem-se a apenas um dia de observações (DOY 083/2011). No arquivo de dados foi selecionado um trecho de 6 horas de dados para a realização dos experimentos, com início às 14:00 e finalização às 20:00 (UTC), contendo um total de 1440 épocas.

O programa para posicionamento DGPS em rede citado em Sejas e Krueger (2008) foi totalmente reescrito em linguagem $\mathrm{C}++$ e preparado para rodar com até 4 estações de referência, onde os coeficientes de rede são estimados pelo método dos mínimos quadrados. Ao final do processo, o programa gera um arquivo no formato RINEX contendo as pseudodistâncias do código, para a estação móvel, corrigidas pelas PRCs geradas na rede e interpoladas para a posição do usuário. $\mathrm{O}$ processamento deste arquivo RINEX foi executado pelo programa apresentado em Sejas (2011) o qual gera ao final um arquivo no formato NMEA-GGA, utilizado nas análises a seguir.

Como são conhecidas as coordenadas precisas das estações SCLA e SCCH, foi possível realizar o cálculo do erro planimétrico para cada uma das 1440 épocas. As Figs. 9 e 10 mostram os gráficos de dispersão e da frequência dos erros, para a estação SCLA, quando utilizada apenas uma estação de referência, no caso a estação IMBT, distantes $170 \mathrm{~km}$ entre si. Verifica-se que $84 \%$ dos erros foram inferiores a $1 \mathrm{~m}$, e $99 \%$ estiveram inferior a $2 \mathrm{~m}$. 




Figura 9 - Dispersão dos erros para a estação SCLA (linha de base simples IMBT $\rightarrow$ SCLA).

\section{DISTRIBUIÇÃO DOS ERROS}

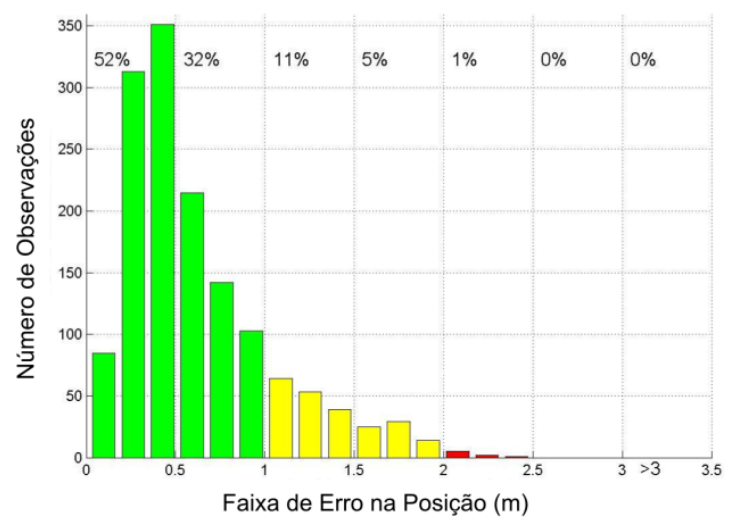

Figura 10 - Distribuição dos erros (acurácia) para a estação SCLA (linha de base simples IMBT $\rightarrow$ SCLA).

Quando utilizadas as informações da rede- nota-se melhora significativa no posicionamento planimétrico, onde $99 \%$ dos erros foram inferiores a $1 \mathrm{~m}$ (Figs. $11 \mathrm{e}$ 12).

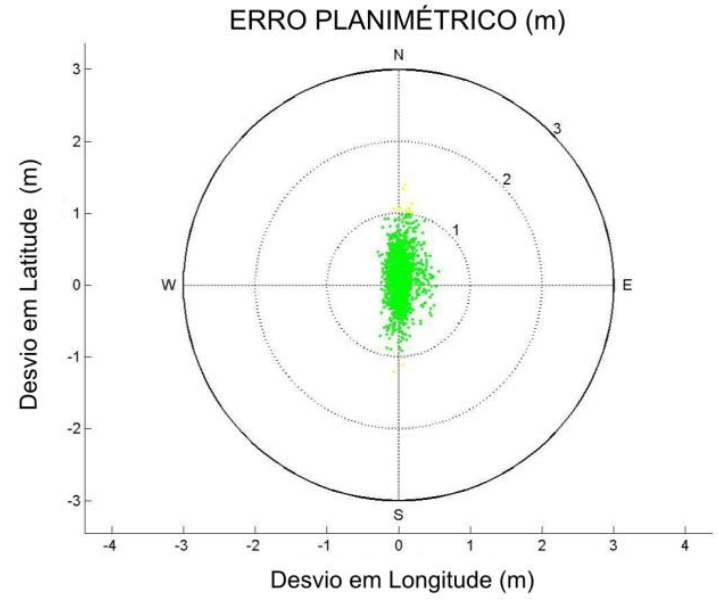

Figura 11 - Dispersão dos erros para a estação SCLA (DGPS em rede).

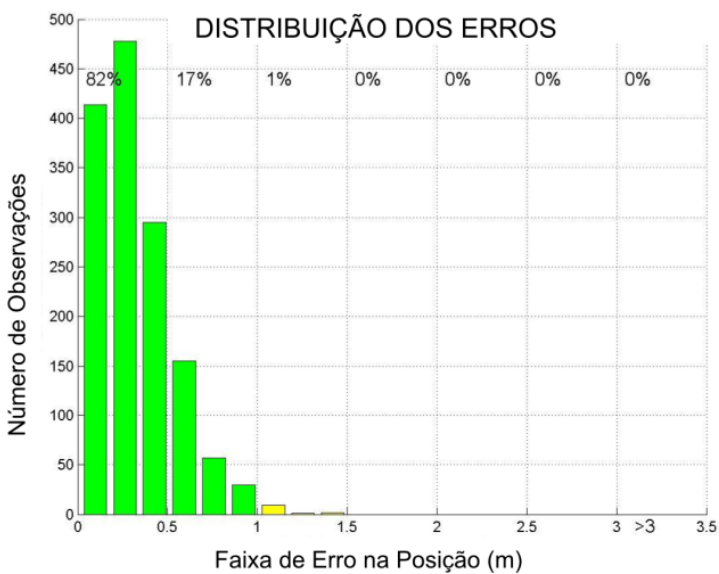

Figura 12 - Distribuição dos erros (acurácia) para a estação SCLA (DGPS em rede).

As mesmas análises foram realizadas para a estação SCCH. Observa-se nas Figs. 13 e 14 que os erros planimétricos foram de magnitude maior que a dos erros percebidos na estação SCLA. Este comportamento era esperado devido à posição geog'rafica da estação em relação à rede.

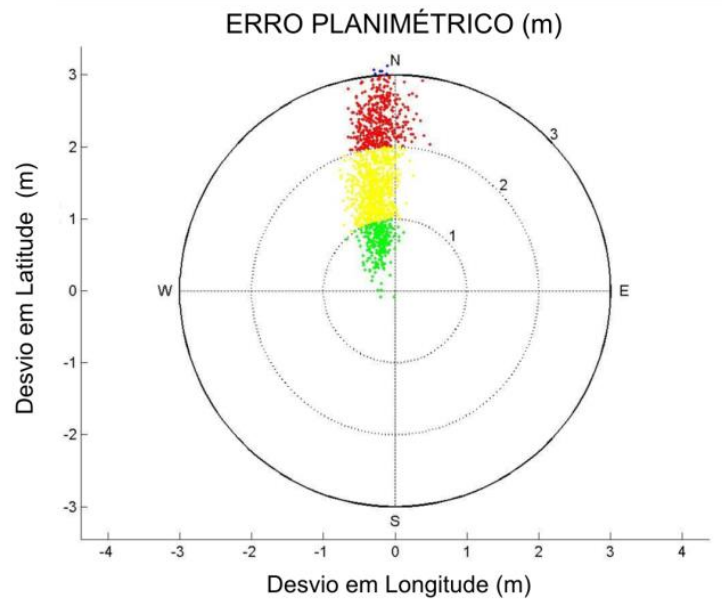

Figura 13 - Dispersão dos erros para a estação SCCH (linha de base simples PRGU $\rightarrow \mathrm{SCCH}$ ).

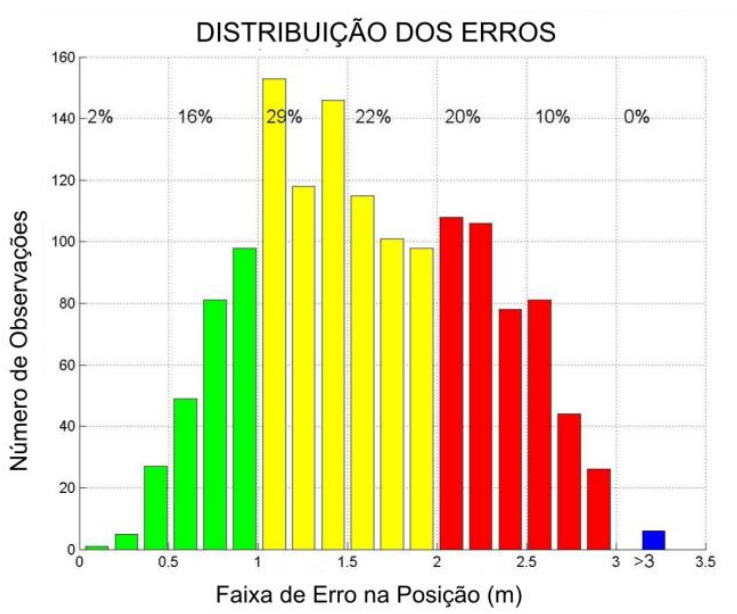

Figura 14 - Distribuição dos erros (acurácia) para a estação $\mathrm{SCCH}$ (linha de base simples PRGU $\rightarrow \mathrm{SCCH}$ ). 
Verifica-se na Fig. 14 que em apenas 18\% das observações o erro planimétrico foi inferior a $1 \mathrm{~m}$. A maior parte dos erros, i.e., $51 \%$, se concentrou entre 1 e $2 \mathrm{~m}$, uma parcela de $30 \%$ dos erros ficou entre 2 e $3 \mathrm{~m}$ e o restante, pouco acima de $3 \mathrm{~m}$. Quando aplicadas as correções geradas em rede, verifica-se novamente uma melhora significativa na distribuição dos erros. Praticamente em $100 \%$ das 1440 observações apresentaram erros planimétricos inferiores a $1 \mathrm{~m}$. Ademais, verifica-se que a tendência na dispersão dos dados (Fig. 13) foi reduzida com o uso de informações de toda a rede, como mostra a Fig. 15.

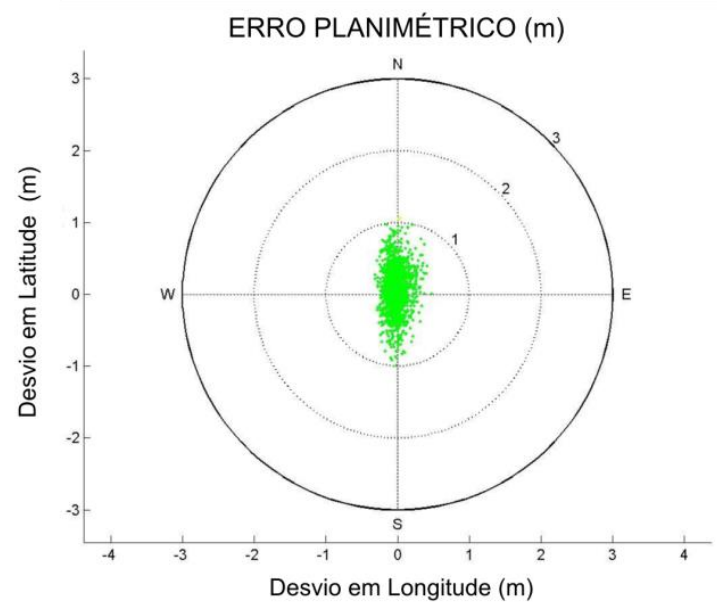

Figura 15 - Dispersão dos erros para a estação SCCH (DGPS em rede).

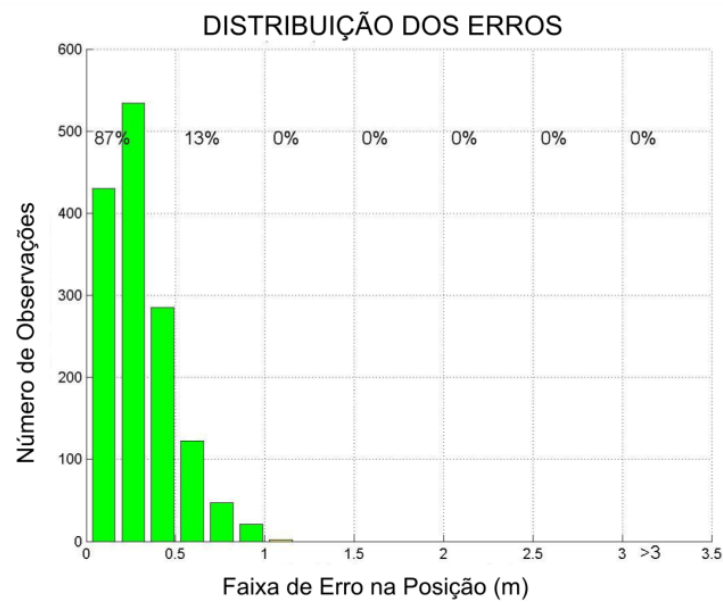

Figura 16 - Distribuição dos erros (acurácia) para a estação SCCH (DGPS em rede)

O quadro 2 mostra as estatísticas referentes ao posicionamento DGPS, i.e., a média do erro planimétrico de todas as observações e o respectivo desvio-padrão, tanto para o posicionamento DGPS em linha de base simples, quanto o DGPS em rede. Constata-se uma considerável melhora no posicionamento quando se aplicam as correções de rede. As médias dos erros planimétricos no posicionamento por linha de base simples, que resultaram $0,57 \mathrm{~m}$ (SCLA) e $1,61 \mathrm{~m}$
$(\mathrm{SCCH})$, passaram a assumir valores inferiores a $0,3 \mathrm{~m}$, indicando melhor acurácia no posicionamento em rede.

O mesmo acontece com os desvios-padrão, que passaram de valores em torno de $0,6 \mathrm{~m}$ a $0,7 \mathrm{~m}$ para valores da ordem de $0,4 \mathrm{~m}$, indicando também melhor precisão no posicionamento em rede.

Quadro 2 - Resultados dos posicionamentos DGPS em rede.
\begin{tabular}{|c|l|c|c|}
\hline Estação & \multicolumn{1}{|c|}{ Estatística } & Simples & Rede \\
\hline SCLA & $\begin{array}{l}\text { Média do Erro } \\
\text { Planimétrico }\end{array}$ & $0,57 \mathrm{~m}$ & $0,29 \mathrm{~m}$ \\
\cline { 2 - 4 } & Desvio-padrão & $0,61 \mathrm{~m}$ & $0,37 \mathrm{~m}$ \\
\hline \multirow{2}{*}{ SCCH } & $\begin{array}{l}\text { Média do Erro } \\
\text { Planimétrico }\end{array}$ & $1,61 \mathrm{~m}$ & $0,26 \mathrm{~m}$ \\
\cline { 2 - 4 } & Desvio-padrão & $0,68 \mathrm{~m}$ & $0,34 \mathrm{~m}$ \\
\hline
\end{tabular}

É importante ressaltar que os experimentos mostrados nesta seção foram realizados no modo pósprocessado. Para posicionamentos em tempo real, deve-se considerar a latência, que contribui na degradação do posicionamento.

\section{CONCLUSÕES}

As técnicas DGPS-NTRIP e DGPS-RDS apresentaram resultados semelhantes, com cerca de $67 \%$ das coordenadas observadas situadas em uma faixa de erro inferior a $2 \mathrm{~m}$ e $100 \%$ delas situadas em uma faixa de erro inferior $4 \mathrm{~m}$. Na técnica DGPS-RDS, cerca de $1 \%$ das observações apresentaram erro superior a $4 \mathrm{~m}$. Com exceção da componente longitude, os desvios-padrão da técnica DGPS-NTRIP apresentaram-se sensivelmente menores. Em termos de acurácia, esta foi cerca de $15 \%$ melhor no DGPS-NTRIP que aquela obtida pelo DGPSRDS.

$\mathrm{Na}$ técnica implementada pelo DGPS em rede, a aplicação das correções geradas promoveram redução na dispersão dos dados e melhora significativa na distribuição dos erros, que foram inferiores a $1 \mathrm{~m}$ em praticamente $100 \%$ de épocas. Os resultados mostraram que o emprego de correções em rede promoveu uma melhora na acurácia entre 1,9 e 5,3 vezes, e uma melhora na precisão entre 1,5 e 1,75 vezes, em comparação ao posicionamento por linha de base simples.

A consistência dos resultados apresentados mostra a viabilidade das técnicas DGPS-RDS e DGPS-NTRIP para o estabelecimento de estratégias visando a sistematização da transmissão de correções diferenciais no país. Entretanto, nos países em que o DGPS-RDS foi sistematicamente implementado, existe a tendência de esta técnica ser substituída pelo DGPS-NTRIP, que no momento se apresenta como uma das opções mais efetivas para a transmissão das correções diferenciais.

De forma geral, por se tratar de um sistema relativamente econômico, moderno e que permite maiores taxas de transmissão de dados (pelo menos relativamente ao RDS), o NTRIP pode ser aplicado não só para DGPS mas também para RTK, método que exige taxas de transmissão de dados mais altas que o DGPS. Assim, este sistema também é a opção mais indicada atualmente no Brasil. 
$\mathrm{O}$ alto custo de implantação de estações de referência no interior do país se justifica não somente para serviços DGPS em rede, como também para serviços que aplicam técnicas RTK em rede. A integração do DGPS em rede aos métodos já existentes de posicionamento em tempo real (RDS e NTRIP) proporcionaria maior precisão e acurácia para as aplicações que necessitam posicionamento da ordem do metro em tempo real.

\section{AGRADECIMENTOS}

Os autores agradecem ao IBGE pela disponibilidade das observações das estações da RBMC, bem como do serviço público de acesso NTRIP, utilizados neste trabalho.

\section{REFERÊNCIAS BIBLIOGRÁFICAS}

ANATEL - Agência Nacional de Telecomunicações RESOLUÇÃO $N^{o} 349$, DE 25 DE SETEMBRO DE 2003. Disponível em:

<http://www.anatel.gov.br/hotsites/Direito_Telecomu nicacoes/TextoIntegral/NOR/res/anatel_20030925_34 9.pdf>

DALBELO, L. F. A. DGPS em rede: desenvolvimento e implantação via internet utilizando a rede GNSS do Estado de São Paulo. Dissertação (mestrado), Universidade Estadual Paulista, Faculdade de Ciências e Tecnologia, Presidente Prudente, 2010.

IBGE - Instituto Brasileiro de Geografia e Estatística. $R B M C-I P$. Disponível em: <http://www.ibge.gov.br/home/geociencias/geodesia/r bmc/ntrip/> Acesso em 31 nov 2012.

GDC - GNSS Data Center. Ntrip Home Page. Disponível em: <http://igs.bkg.bund.de/ntrip/index> Acesso em 31 nov 2012.

GEBHARD, H.; WEBER, G. Networked Transport of RTCM via Internet Protocol. Design-ProtocolSoftware. Federal Agency for Cartography and Geodesy, June, 2003.

GUTERRES, S. D. R., SAATKAMP, E. D. S. Investigações sobre posicionamentos pelo método DGPS usando transmissão das correções diferenciais pelo NTRIP e pelo RDS. Revista Geomática, vol. 4, $\mathrm{n}^{\circ}$ 2, p. 73 a 86. Programa de Pós-Graduação em Geomática. UFSM, Santa Maria, 2009.

HOFMANN-WELLENHOF, B.; LICHTENEGGER, H.; COLLINS, J. GPS theory and practice. Fifth, revised edition, SpringerWienNewYork, 2001.

OGATA, T.; SAKATA, N.; FUJIWARA A.; OKUDA, M. Radio Data System (RDS). UDC 621.396.4:629.113. Fujitsu Ten Tech. J., N. 5, 1992.

SAATKAMP, E. D. Desenvolvimento e experimentação de um formato para a transmissão de correções DGPS pelo RDS no Brasil. Tese de Doutorado em Ciências Geodésicas - Universidade Federal do Paraná, Curitiba, 2003, 162 p.

SAATKAMP, E. D.; FREIBERGER JR, J.; SEJAS, M. I.; MORAES, C. V.; MAYER, M.; FARRET, J. C. Differential post-processed positioning based on continuously operating GNSS networks adapted to the Brazilian environment. 5. Deutsch-Brasilianisches Symposium für Nachhaltige Entwicklung. Universität Stuttgart, 18-22 jul. 2011.

SEEBER, G., Satellite Geodesy: foundations, methods, and applications. Berlin: Walter de Gruyter, 2003, $589 \mathrm{p}$.

SEJAS, M. I. Desenvolvimento de um programa GPS para o posicionamento por ponto. VI Colóquio Brasileiro de Ciências Geodésicas Curitiba, 12 a 14 de setembro de 2011.

SEJAS, M. I.; KRUEGER, C. P. Posicionamento diferencial pós-processado utilizando multiestações GPS. II Simpósio Brasileiro de Ciências Geodésicas e Tecnologias da Geoinformação. Recife - PE, 8-11 de setembro de 2008.

WÜBBENA, G.; BAGGE, A.; SCHMITZ, M. Networkbased techniques for RTK applications. Presented at the GPS Symposium, GPS JIN 2001, GPS Society, Japan Institute of Navigation, Tokyo, Japan, November 14-16, 2001. 